\title{
LncRNA ASAP1-IT1 enhances cancer cell stemness via regulating miR-509-3p/YAP1 axis in NSCLC
}

Yantao Liu' ${ }^{1,2,3}$, Yuping Yang ${ }^{4}$, Lingli Zhang ${ }^{1,2,3}$, Jiaqiang Lin ${ }^{5}$, Bin Li ${ }^{5}$, Min Yang ${ }^{5}$, Honghui Li ${ }^{7}$, Kangwu Chen ${ }^{6^{*}}$ and Wei Zhao ${ }^{5,8^{*}}$ (D)

\begin{abstract}
Background: Non-small cell lung cancer (NSCLC) is a major cause of cancer-related death worldwide, and cancer stem cell is responsible for the poor clinical outcome of NSCLC. Previous reports indicated that long noncoding RNAs (IncRNAs) play important roles in maintaining cancer stemness, however, the underlying mechanisms remain unclear. This study investigates the role of ASAP1 Intronic Transcript 1 (ASAP1-IT1) in cancer cell stemness of NSCLC.

Methods: The expression of ASAP1-IT1, microRNA-509-3p (miR-509-3p) and apoptosis-/stemness-related genes was analyzed by qRT-PCR in NSCLC tissues, cancer cells and spheres of cancer stem cells. Knockdown of ASAP1-IT1 or overexpression of miR-509-3p in NSCLC cells by infection or transfection of respective plasmids. Sphere formation and colony formation were used to detect NSCLC stem cell-like properties and tumor growth in vitro. Luciferase reporter assays, RNA immunoprecitation (RIP) and qRT-PCR assays were used to analyze the interaction between IncRNA and miRNA. The expression of expression of regulated genes of ASAP1-IT1/miR-509-3p axis was evaluated by qRT-PCR and Western blot. The NSCLC xenograft mouse model was used to validate the role of ASAP1-IT1 in NSCLC stemness and tumor growth in vivo.
\end{abstract}

Results: ASAP1-IT1 was up-regulated in NSCLC tissues, cancer cells, and in spheres of A549-derived cancer stem cells. Downregulation of ASAP1-IT1 or overexpression of miR-509-3p significantly decreased cell colony formation and stem cell-like properties of A549-dereived stem cells with decreased expression of stem cell biomarkers SOX2, CD34, and CD133, and suppressing the expression of cell growth-related genes, Cyclin A1, Cyclin B1, and PCNA. Furthermore, knockdown of ASAP1-IT1 or overexpression of miR-509-3p repressed tumor growth in nude mice via reducing expression of tumorigenic genes. ASAP1-IT1 was found to interact with miR-509-3p. Moreover, overexpression of ASAP1-IT1 blocked the inhibition by miR-509-3p on stem cell-like properties and cell growth of A549-dereived stem cells both in vitro and in vivo. Finally, the level of YAP1 was regulated by ASAP1-IT1 and miR-509-3p.

Conclusions: YAP1-involved ASAP1-IT1/miR-509-3p axis promoted NSCLC progression by regulating cancer cell stemness, and targeting this signaling pathway could be is a promising therapeutic strategy to overcome NSCLC stemness.

\footnotetext{
*Correspondence: kangwuchen2008@hotmail.com;wzhao42@cityu.edu.hk

${ }^{5}$ School of Laboratory Medicine Chengdu Medical College, Chengdu,

China

${ }^{6}$ Department of Orthopedic Surgery, The First Affiliated Hospital

of Soochow University, Suzhou, China

Full list of author information is available at the end of the article
}

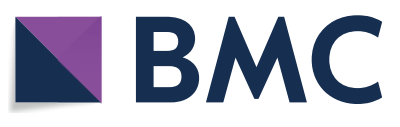

Author(s) 2021. Open Access This article is licensed under a Creative Commons Attribution 4.0 International License, which permits use, sharing, adaptation, distribution and reproduction in any medium or format, as long as you give appropriate credit to the original author(s) and the source, provide a link to the Creative Commons licence, and indicate if changes were made. The images or other third party material in this article are included in the article's Creative Commons licence, unless indicated otherwise in a credit line to the material. If material is not included in the article's Creative Commons licence and your intended use is not permitted by statutory regulation or exceeds the permitted use, you will need to obtain permission directly from the copyright holder. To view a copy of this licence, visit http://creativecommons.org/licenses/by/4.0/. The Creative Commons Public Domain Dedication waiver (http://creativeco mmons.org/publicdomain/zero/1.0/) applies to the data made available in this article, unless otherwise stated in a credit line to the data. 
Keywords: ASAP-IT1, miR-509-3p, YAP1, Cancer stemness, NSCLC

\section{Background}

Non-small cell lung cancer (NSCLC) is the major type of lung cancer which is a leading course of cancer-related death worldwide [1]. Although the treatment of NSCLC has been improved, the 5 -years survival rate remains low owing to cancer relapse after surgery or radiotherapy [2, $3]$. Therefore, it is critical to better understand the molecular mechanisms of NSCLC progression and find out biomarkers to identify indolent and aggressive tumors, to provide novel therapeutic strategies.

Increasing evidence have demonstrated that the recurrence of NSCLC is mostly induced by cancer stem cells in tumors [4-6]. Cancer stem cells are involved in cancer initiation, proliferation, invasion, and differentiation, resulting in occurrence of aggressive and metastatic cancers [7]. Simultaneously, cancer stem cells can bring about multi-drug resistance in NSCLC [8]. Thus, it is interesting and meaningful to investigate the association of cancer stem cell and NSCLC progression, that would create therapeutic strategies.

Long noncoding RNAs (lncRNAs) are involved in the progression of multiple cancers including NSCLC [9-13]. AFAP1-AS1 (Actin Filament Associated Protein 1 Antisense RNA 1) is a lncRNA which promotes NSCLC cell proliferation by epigenetically suppressing p21 expression [14]. Linc00673 (long intergenic non-protein coding RNA 673) modulates NSCLC cell proliferation, migration, invasion and epithelial mesenchymal transition via sponging miR-150-5p [15]. Linc00473 (long intergenic non-protein coding RNA 473), regulated by cAMP/ CREB (adenosine monophosphate/cAMP-response element binding protein), and LKB1 (liver kinase B1) inhibits lung cancer and controls tumor growth [16]. Furthermore, lncRNAs also affect the stemness of lung cancer cells. DGC5 (DiGeorge syndrome critical region gene 5) contributes to cancer cell stemness-like properties by regulating miR-330-5p/CD44 in NSCLC [17]. Linc00662 (long intergenic non-protein coding RNA 662) increases cancer stem cell-like phenotypes in lung cancer [18]. FENDFRR (FOXF1 adjacent non-coding developmental regulatory RNA) inhibits cancer cell stemness by repressing expression of MDR1 (multi-drug resistance gene 1) by interacting with the RNA binding protein $\mathrm{HuR}$ in NSCLC development [19]. Linc-ITGB1 (long intergenic non-protein coding RNA integrin subunit beta 1 ) decreases cancer stemness via down-regulating Snail in NSCLC [20]. HAND2-AS1 (heart and neural crest derivatives expressed 2 antisense RNA 1) elevates cancer cell stemness of lung cancer cells via binding to TGF-beta1 (transforming growth factor beta1) [21]. Interestingly, lncRNA ASAP1-IT1 (ArfGAP with SH3 domain, ankyrin repeat and $\mathrm{PH}$ domain 1intronic transcript 1) increases cell proliferation, invasion, and metastasis by regulating PTEN/AKT (phosphatase and tensin homolog/AKT serine/threonine kinase 1) axis in NSCLC [22]. ASAP1-IT1 enhances stemness of cancer cells, and overexpression of ASAP1-IT1 indicates a poor prognosis in patients with bladder cancer [23]. In addition, ASAP1-IT1 promotes development of cholangiocarcinoma through hedgehog signaling pathway [24]. However, the role of ASAP1-IT1 on cancer cell stemness in NSCLC is largely unknown.

In this study, we explored the role of ASAP1-IT1 in NSCLC progression. The binding of ASAP1-IT1with miRNAs was predicted using LncBook database (a curated knowledgebase of human long non-coding RNAs) (https://bigd.big.ac.cn/lncbook/index). We found that miR-509-3p was a potential target of ASAP1-IT1. Previous studies demonstrated that miR-509-3p functions as a tumor suppressor. For instance, miR-509-3p increases platinum drug sensitivity to induce cell apoptosis in ovarian cancer [25, 26]. MiR-509-3p suppresses cell proliferation and migration by up-regulating XIAP (X-linked inhibitor of apoptosis) in gastric cancer [27]. MiR-509-3p represses cell proliferation and invasion by decreasing XIAP in glioma [28]. MiR-509-3p is downregulated by the oncoprotein HBXIP (late endosomal/ lysosomal adaptor, MAPK and MTOR activator 5) via activating NF- $\mathrm{kB}$ in hepatoma cells. Additionally, the potential targets of miR-509-3p were predicted using Target Scan tools, and the results showed that YAP1 (Yes associated protein 1) was a downstream target of miR509-3pin NSCLC cells. YAP1 has been considered as an oncogene in multiple cancers including NSCLC [29-33]. YAP1 positively regulates drug resistance and cancer cell stemness [29, 30]. Also, YAP1is the main effector of the Hippo signaling pathway involved in human cancers [34].

In this study, we investigate the role of ASAP1-IT1, and the association of ASAP1-IT1, miR-509-3p and YAP1 in NSCLC progression and cancer cell stemness.

\section{Materials and methods}

\section{Clinical specimens}

The NSCLC specimens were collected from 83 patients who were treated in the First Affiliated Hospital of Chengdu Medical College (Chengdu, China) from April in 2019 to September in 2020. The collection of clinical samples was approved by the ethics committee of Chengdu Medical College (approved ID: BR20re19), and 
each participant signed an informed consent form. All the patients were given no treatment before surgery. The collected specimens were stored in a liquid nitrogen tank.

\section{Cell maintenance and transfection}

The A549 and A549/R (cisplatin resistant) cells were obtained from China Infrastructure of Cell Line Resource (Beijing, China), and cultured in DMEM (Dulbecco's Modified Eagle Medium) media (WISENT, Nanjing, Jiangsu, China) in a $\mathrm{CO}_{2}$ incubator at $37^{\circ} \mathrm{C}$. The DMEM media was supplemented with $10 \%$ FBS (fetal bovine serum), $100 \mathrm{mg} / \mathrm{mL}$ streptomycin and $100 \mathrm{U} / \mathrm{mL}$ penicillin (WISENT). The FBS was bought from Thermo Fisher Scientific (Waltham, Massachusetts, USA). All the other cell culture materials were bought from WISENT.

The cell infection was conducted according to the manufacturer's instruction (Genechem, Shanghai, China). sh-ASAP1-IT1: 5'-GCU GCG ACA AUA GAC AUC GGA GUU U-3', and sh-NC: $5^{\prime}$-CUC UCG GAA CAU GUC ACA U-3'. The mimic microRNAs and inhibitors were purchased from Ribobio (Guangzhou, China), miR509-3p-related sequences were listed, Mock, 5'-UCU CCG AAC GUG UCA CGU U-3'; and anti-miR-509-3p, 5'-CCG UGG UUC AUA CUG GUA-3'; miR-509-3p mimic, $5^{\prime}$-UAC CAC AGG GUA GAA CCA CGG- ${ }^{\prime}$. The pmirGLO-ASAP1-IT1-WT (wild type) or -Mut (Mutant), and pmirGLO-Yap1-3'UTR (untranslated region)-WT or -Mut (Mutant), and pcDNA-sh-NC, pcDNA-sh-ASAP1IT1 were obtained from Thermo Fisher Scientific.

\section{Hematoxylin-eosin (H\&E) staining}

The NSCLC specimens were fixed in $4 \%$ paraformaldehyde, embedded in paraffin and subjected to sectioning. Then, H\&E staining was performed as described previously [10]. All the chemicals and reagents were bought from Servicebio (Wuhan, Hubei, China).

\section{RNA extraction and qRT-PCR (quantitative real time polymerase chain reaction)}

The total RNA was extracted using TRIzol reagent (Life Technologies, Rockville, MD, USA). The reverse transcription kit (Thermo Fisher Scientific) was applied to synthesize cDNA (complementary DNA) from the total RNA. Quantitative RT-PCRs were used to evaluate the levels of miRNAs, lncRNAs, or mRNAs using the SYBR Premix Ex Taq II (TaKaRa, Dalian, China). The qRT-PCR was carried out under the thermal cycling conditions: $95^{\circ} \mathrm{C} \times 5 \mathrm{~min}$, and 40 cycles of $95^{\circ} \mathrm{C} \times 30 \mathrm{~s}, 60{ }^{\circ} \mathrm{C} \times 30 \mathrm{~s}$, and $72{ }^{\circ} \mathrm{C} \times 1 \mathrm{~min}$. GAPDH (glyceraldehyde-3-phosphate dehydrogenase) was used as the internal control for RNA and IncRNA, and U6 was used as the internal control of miRNAs. The relative RNA levels were calculated following the $2^{-\Delta \Delta C T}$ method. The PCR primers were list in Table 1. All experiments were performed in quadruplicate, and each assay was repeated independently for 3 times.

\section{Western blot}

Total protein samples were prepared from the tissues or cells using RIPA (radio immunoprecipitation assay) buffer (Beyotime) for $30 \mathrm{~min}$. The lysates were centrifuged at $12,000 \times g$ for 15 min to obtain the supernatants, and they were de-natured at $98{ }^{\circ} \mathrm{C}$ for $20 \mathrm{~min} .50 \mu \mathrm{g}$ proteins were used for sodium dodecyl sulfate-polyacrylamide gel electrophoresis (SDS-PAGE) (Bio-Rad, Hercules, CA, USA). All the prepared gels were transferred to the $0.22 \mu \mathrm{m}$ PVDF (polyvinylidene difluoride) membranes (Thermo Fisher Scientific) for $2 \mathrm{~h}$, and the proteins-carried PVDF

Table1 The used PCR primers in this study

\begin{tabular}{|c|c|c|}
\hline Gene name & Forward primer $\left(5^{\prime}-3^{\prime}\right)$ & Reverse primer $\left(5^{\prime}-3^{\prime}\right)$ \\
\hline U6 & TGC GGG TGC TCG CTT CGG CAG C & GTG CAG GGT CCG AGG T \\
\hline miR-509-3p & UAC CAC AGG GUA GAA & CTC TAC AGC TAT ATT GCC AGC CA \\
\hline GAPDH & CAC CCA CTC CTC CAC CTTTG & CCA CCA CCC TGT TGC TGT AG \\
\hline Cyclin A1 & ATA ACG ACG GGA AGA GCG G & CAG GGT ACA TGA TTG CGG GA \\
\hline Cyclin B1 & CAG GTT GTT GCA GGA GAC CA & CAT GGC AGT GAC ACC AAC CA \\
\hline PCNA & CGC CCT GGTTCT GGA GGT AA & GGC TGA GAC TTG CGT AAG GG \\
\hline $\mathrm{BCl}-2$ & TTC TTT GAG TTC GGT GGG GT & GAA ATC AAA CAG AGG CCG CAT \\
\hline Bax & GGG TTG TCG CCC TTTTCT AC & AGT CGC TTC AGT GAC TCG G \\
\hline YAP1 & TGC TGT CCC AGA TGA ACG TC & GGT TCA TGG CAA AAC GAG GG \\
\hline ASAP1-IT1 & AAA CAT CAT CCC CAG AGT GG & GCC TTG CTC ACC TCT GAA AC \\
\hline sox2 & CAT GAA GGA GCA CCC GGA TT & ATG TGC GCG TAA CTG TCC AT \\
\hline CD44 & GCC ACC AGA GCT ATT CCC AA & GGT CTT CGC CCA GCC TTT CT \\
\hline CD133 & GCC ATG CTC TCA GCT CTC C & TCC TGA AAA GGA GTT CCC GC \\
\hline
\end{tabular}


were blocked with $1 \%$ bovine serum albumin. Then, the PVDF membranes were incubated with the primary antibody overnight in a $4{ }^{\circ} \mathrm{C}$ refrigerator. The membranes were incubated with the HRP (horseradish peroxidase)conjugated secondary antibody diluted at 1:50,000 (Bioworld Technology, Nanjing, China; Goat Anti-Rabbit IgG, Cat No. BS10550; Goat Anti-Mouse IgG, Cat No. BS12471) for $1 \mathrm{~h}$. The anti-YAP1 (Cat No. MA5-32117), anti- $\beta$-Actin (Cat No. PA1-183-HRP), anti-Bax (Cat No. MA5-14003), anti-Bcl-2 (Cat No. MA5-11757), and Cleaved-caspase-3 (Cat No. MA5-32134) were bought from Thermo Fisher Scientific.

\section{Sphere formation and colony formation of cancer stem cells}

Cancer stem cells were sorted from A549 cells or transfected-A549 cells by sphero-cyst medium [10], and the sorted cancer stem cells from A549 were named as A549derived stem cells. The $3 \times 10^{4}$ cells were seeded in 6 -well ultra-low cluster plates (Thermo Fisher Scientific). They were maintained in DMEM/F12 serum free medium (Thermo Fisher Scientific) containing epidermal growth factor $(20 \mathrm{ng} / \mathrm{mL})$, beta-fibroblast growth factor $(20 \mathrm{ng} /$ $\mathrm{mL})$, insulin $(4 \mu \mathrm{g} / \mathrm{mL})$, and B27 (2\%). All reagents were from Sigma. Finally, the number of spheres was counted under an inverted microscope (Leica, Oskar-BarnackStraße, Germay) post 10 days incubation. The biomarkers of cancer stem cells SOX2, CD34, and CD133 were used to identify the cancer stem cells using qRT-PCR and Western blot.

The A549 cancer stem cells were isolated using magnetic bead kit, and $3 \times 10^{4}$ stem cells were seeded in sixwell plates with ultra-low adhesion. They were cultured in sphere formation media for a week, and post another 20 days, the number of spheres was calculated under a microscope.

\section{Cell apoptosis and cell cycle analysis}

To determine cell apoptosis of A549-dereived stem cells and other cells, cells were collected at $80 \mathrm{~g} \times 4{ }^{\circ} \mathrm{C} \times 5 \mathrm{~min}$ for annexin-V/FITC (fluoresceine isothiocyanate)/PI (propidium iodide) staining after $48 \mathrm{~h}$ infection with the indicated plasmids or miRNAs. Briefly, cells were incubated with annexin- $\mathrm{V}$ and PI for $10 \mathrm{~min}$ and $5 \mathrm{~min}$, respectively, in a dark room using the annexin V-FITC/ PI staining kit (Beyotime, Beijing, China). Finally, the cell cycle was evaluated using the Beckman Coulter Navios EX flow cytometry (Beckman, Shanghai, China).

For analyzing cell cycle, the cells were cultured in 12-well plates (Thermo Fisher Scientific). After transfection with the indicated miRNAs or plasmids for $48 \mathrm{~h}$, they were subjected to suspension and fixation in $75 \%$ ethanol at $4{ }^{\circ} \mathrm{C}$ for $12 \mathrm{~h}$. Then, they were washed with
PBS (phosphate-buffered saline) for 3 times. Afterwards, they were resuspended in $500 \mu \mathrm{L}$ staining buffer containing propidium iodide $(5 \mathrm{mg} / \mathrm{mL}) /$ RNase $(10 \mathrm{mg} / \mathrm{mL})$ at $37{ }^{\circ} \mathrm{C}$ for $30 \mathrm{~min}$ in a dark room. Finally, cell apoptosis rate was evaluated using the flow cytometry. Each treatment group consisted four wells, and each assay was repeated for 3 times independently.

\section{Cell counting kit-8 (CCK-8) assay}

The A549-dereived stem cells or A549 cells were plated into a 96-well plate (Thermo Fisher Scientific) at the density of $4 \times 10^{3}$ cells per well for determination of cell viability. CCK-8 reagent (Sangon, Shanghai, China) were added into medium after the cells were cultured $36 \mathrm{~h}$. After incubation for $1 \mathrm{~h}$ at $37^{\circ} \mathrm{C}$, the formation of watersoluble formazan was examined in a microplate reader (Bio-Rad) with the light length of $450 \mathrm{~nm}$. All experiments were performed in quadruplicate, and each assay was repeated independently for 3 times.

\section{Dual luciferase reporter assay}

To determine the effects of miR-509-3p on luciferase activity of pmirGLO-ASAP1-IT1, $2 \times 10^{4}$ A549 cells per well were seeded in 24-well plates. They were cotransfected with pmirGLO-ASAP1-IT1-WT (wild type), pmirGLO-ASAP1-IT1-Mut (Mutant), as well as Mock (negative control), miR-509-3p mimic, and anti-miR509-3p. To examine the effects of miR-509-3p on luciferase activity of pmirGLO-Yap1-3'UTR, the cells were co-transfected with pmirGLO-Yap1-3' UTR-WT, pmirGLO-Yap1-3' UTR-Mut (Mutant), as well as Mock, miR509-3p mimic, and anti-miR-509-3p. After transfection for $48 \mathrm{~h}$, they were collected and lysed. The supernatants were used for measurement of luciferase activity using the Dual-Luciferase Assay Kit on GloMax 20/20 Luminometer following the manufacturer's instructions (Promega, Madison, USA). All experiments were performed in quadruplicate, and each assay was repeated independently for 3 times.

\section{RNA immunoprecipitation (RIP) assay}

RIP assay was conducted to examine the interaction between ASAP1-IT1 and miR-509-3p using the RIP RNA-binding protein immunoprecipitation kit Magna (Millipore, Massachusetts, USA). Briefly, the cell lysate was incubated with anti-Ago2 (argonaute-2), and antiIgG was used as a negative control. The antibodies were purchased from Bioworld Technology (Nanjing, China). At last, the collected immunoprecipitated RNA samples were used to determine ASAP1-IT1 and miR-1301-3p content by qRT-PCR analysis. All experiments were performed in quadruplicate, and each assay was repeated independently for 3 times. 


\section{Mouse tumorigenesis assay}

The A549-dereived stem cells were infected with the mentioned shRNAs or plasmids as indicated. Post $48 \mathrm{~h}$ infection, the A549-dereived stem cells were collected at $80 \mathrm{~g} \times 4{ }^{\circ} \mathrm{C} \times 5 \mathrm{~min}$. Afterwards, $4 \times 10^{6}$ cells were inoculated into 5 -week-old nude mice. The BALB/c nude mice were bought from the Model Animal Research Center of Nanjing University (Nanjing, China), and divided randomly with 3 mice in each group. The animal experiments were approved by the research ethics committee of Chengdu Medical College (approved animal protocol No. CMC20LM22). The tumor volume was calculated every 3 days using the formula, tumor volume $=\left(\right.$ length $\times$ width $\left.^{2}\right) / 2$. All the tumor-carried nude mice were sacrificed on the 24th day post inoculation.

\section{Statistical analysis}

Statistical analysis was conducted using SPSS software package (version 20.0, SPSS Inc., NY, USA) and GraphPad Prism 6 (GraphPad Software, CA, USA). A p value $<0.05$ was considered statistically significant. The data were obtained from three independent experiments, and all data were expressed as mean \pm standard deviation (S.D.). The statistical significance was examined using Two-tailed Student's t-test for two-group comparisons and one-way analysis of variance (ANOVA) test with post-hoc analysis for multi-group comparisons.

\section{Results}

\section{ASAP1-IT1 is overexpressed in NSCLC tissues} and knockdown of ASAP1-IT1 inhibited stemness of NSCLC cells

To evaluate the role of ASAP1-IT1 in NSCLC, we determined the ASAP1-IT1 expression in human NSCLC specimens and adjacent tissues using qRT-PCR. The $H \& E$ staining confirmed the dysregulated cancerous growth in NSCLC tissues (Fig. 1A). The qRT-PCR results demonstrated that ASAP1-IT1 was significantly overexpressed in NSCLC tissues compared with that in adjacent tissues (Fig. 1B), High expression of ASAP1-IT1 (> mean value of all tumors) was positively correlated with tumor differentiation, TNM stage, and lymph node metastasis (Table 2). Meanwhile, ASAP1-IT1 was also up-regulated in NSCLC cells (A549, Calu-3, PC-9, and SPCA-1) (Fig. 1C). To investigate the role of ASAP1-IT1 in inducing stemness in NSCLC, we determined the ASAP1-IT1 expression between parental A549 cells and stemnessenriched A549 spheres. The qRT-PCR data showed that ASAP1-IT1 was markedly elevated in spheres of A549-dereived stem cells compared with the parental group (Fig. 1D). Meanwhile, stemness-associated genes including SOX2, CD44, CD133 were increased in A549 spheres compared with that in parental cells (Fig. 1E). To explore the function of ASAP1-IT1 in stemness formation, the ASAP1-IT1 expression was knocked down in A549-dereived stem cells (Fig. 1F). The qRT-PCR analysis showed that knockdown of ASAP1-IT1 significantly down-regulated expression of stemness-associated genes SOX2, CD44, and CD133 in A549-dereived stem cells (Fig. 1G). Furthermore, suppression of ASAp1-IT1 significantly reduced sphere formation in comparison to the pcDNA-sh-NC group (Fig. 1H, I). Additionally, downregulation of ASAP1-IT1 arrested A549-dereived stem cells in G0/G1 phase (Fig. 1J).

\section{Knockdown of ASAP1-IT1 suppressed cell growth and reduced cisplatin resistance in cancer stem cells, and promoted apoptosis}

Cancer stem cells (CSCs) are closely associated with chemo-resistance, which often reduces therapeutic effects of anti-cancer drugs, such as cisplatin. To examine whether ASAP1-IT1 serves as a dominant factor of cisplatin resistance in NSCLC cells, A549 cells with ASAP1-IT1-knockdown were incubated with $4 \mu \mathrm{M}$ cisplatin. The qRT-PCR data showed that ASAP1-IT1 was increased after incubation with cisplatin in a timedependent manner (Fig. 2A). Also, ASAP1-IT1 was upregulated in A549/R cells compared with that in A549 cells (Fig. 2B). ASAP1-IT1-knockdown A549 cells were then incubated with cisplatin at different concentration, and the CCK- 8 assays demonstrated that increasing concentration of cisplatin significantly decreased cell viability of A549 cells with ASAP1-IT1-knockdown (Fig. 2C). Moreover, annexin V-FITC/PI assays and qRT-PCR analysis confirmed that ASAP1-IT1 knockdown obviously increased apoptotic cells of A549 by elevating expression of Bax and caspase-3, and inhibiting Bcl-2 expression (Fig. 2D-F). Knockdown of ASAP1-IT1 also repressed colony formation of A549-dereived stem cells (Fig. 2G, $\mathrm{H})$, and silencing ASAP1-IT1 expression significantly decreased expression of cell growth-associated genes including Cyclin A1, Cyclin B1, and PCNA (Fig. 2I).

\section{ASAP1-IT1 reciprocally interacted with miR-509-3p}

To find out the molecular mechanisms of ASAP1-IT1 in regulating NSCLC progression, we predicted its potential interaction with miRNAs using LncBook database (a curated database of human long non-coding RNAs) (https://bigd.big.ac.cn/lncbook/index). It was found that miR-509-3p might be a target miRNA of ASAP1IT1 (Fig. 3A). In the meantime, miR-509-3p was found to be downregulated in NSCLC tissues, and its expression was negatively correlated with ASAP1-IT1 (Fig. 3B, C). In addition, ASAP1-IT1 significantly suppressed miR-509-3p expression in A549 cells (Fig. 3D). Furthermore, miR-509-3p inhibited luciferase activity of 


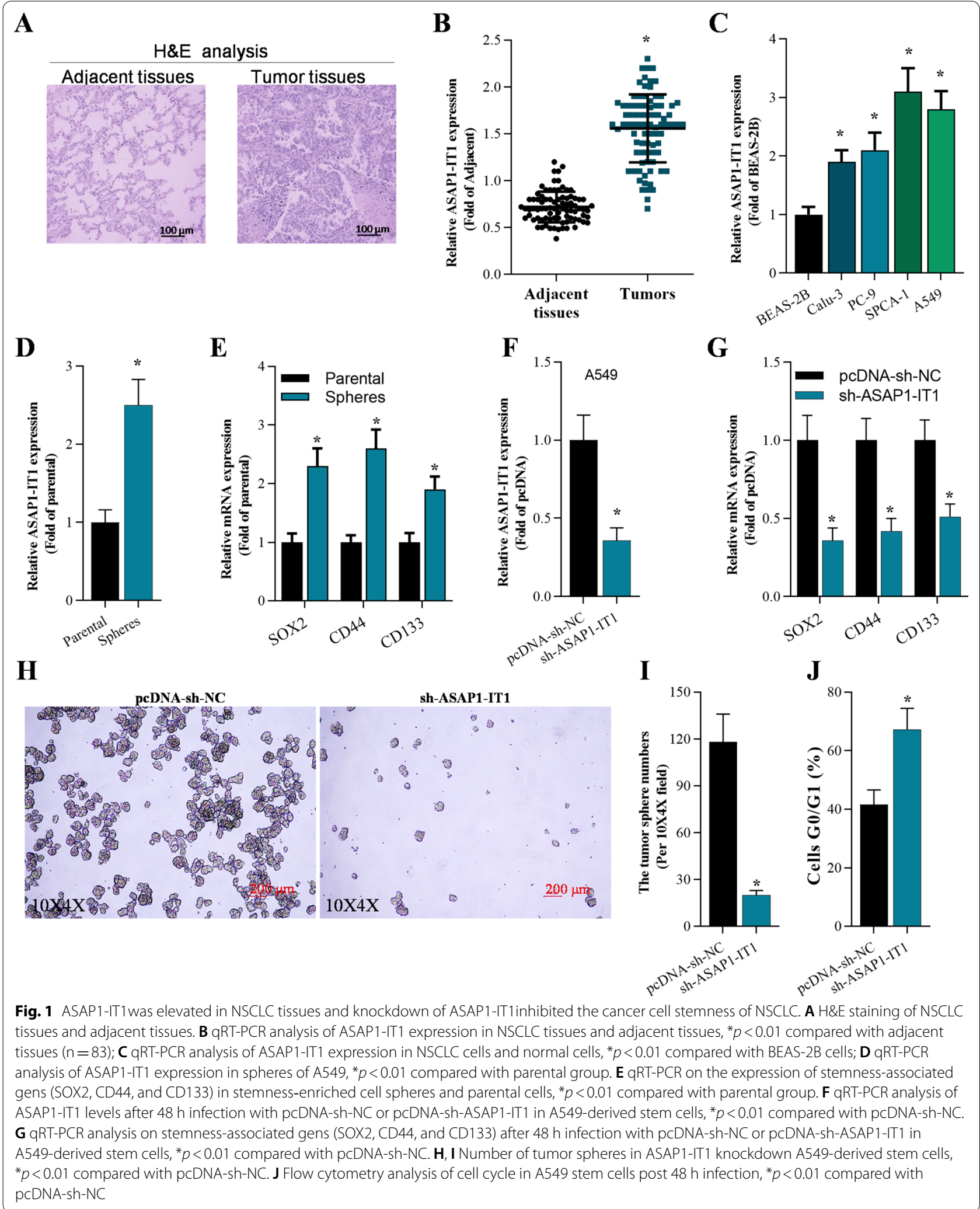


Table 2 Association between IncRNA ASAP1-IT1 expression to clinical characteristics in the NSCLC tissues

\begin{tabular}{|c|c|c|c|}
\hline Factor & $\begin{array}{l}\text { ASAP1-IT1 } \\
\text { level (low) }\end{array}$ & $\begin{array}{l}\text { ASAP1-IT1 } \\
\text { level (high) }\end{array}$ & $P$-value \\
\hline Sex & & & 0.327 \\
\hline Male & 22 & 25 & \\
\hline Female & 17 & 19 & \\
\hline Age & & & 0.431 \\
\hline$\leq 60$ & 23 & 24 & \\
\hline$>60$ & 18 & 18 & \\
\hline \multicolumn{4}{|l|}{ Smoking status } \\
\hline Yes & 20 & 24 & 0.297 \\
\hline No & 17 & 22 & \\
\hline Histology & & & 0.506 \\
\hline SSC & 21 & 23 & \\
\hline$A C$ & 20 & 19 & \\
\hline Others & 0 & 0 & \\
\hline Tissue differentiation & & & 0.012 \\
\hline Middle and high & 6 & 37 & \\
\hline Low & 8 & 32 & \\
\hline TNM stage & & & 0.015 \\
\hline$|/| \mid$ & 12 & 34 & \\
\hline III/IV & 7 & 30 & \\
\hline Lymph node metastasis & & & 0.013 \\
\hline Present & 14 & 28 & \\
\hline Absent & 11 & 30 & \\
\hline
\end{tabular}

ASAP1-IT1 ArfGAP with SH3 domain, ankyrin repeat and PH domain 1 intronic transcript 1, NSCLC non-small cell lung cancer, SCC lung squamous cell carcinoma, $A C$ lung adenocarcinoma

A $P$ value $<0.05$ was statistically significant

pmirGLO-ASAP1-IT1-WT, and miR-509-3p failed to affect the luciferase activity of pmirGLO-ASAP1-IT1Mut, which contained the mutated binding sites of miR-509-3p on ASAP1-IT1 (Fig. 3E, F). Moreover, overexpression of miR-509-3 repressed ASAP1-IT1 level while inhibition of miR-509-3p elevated ASAP1-IT1 expression (Fig. 3G).To confirm the direct interaction between miR-509-3p and ASAP1-IT1, RIP assay was conducted. The results supported that ASAP1-IT1 could interact with miR-509-3p in A549 cells (Fig. 3H).

\section{Overexpression of miR-509-3p inhibited cancer cell} stemness, cisplatin resistance and cell growth of A459 stem cells, and promoted apoptosis

The roles of miR-509-3p in cancer cell stemness, cisplatin resistance, cell growth, and cell apoptosis were investigated both in vitro and in vivo. Quantitative RT-PCR analysis demonstrated that miR-509-3p was reduced in the spheres of A549 cells compared with the parental cells (Fig. 4A). Meanwhile, overexpression of miR509-3p significantly inhibited stemness-associated genes
SOX2, CD44, and CD133 in A549-dereived stem cells compared with that in the Mock group (Fig. 4B). Overexpression of miR-509-3p suppressed sphere formation in comparison to Mock-transfected A549-dereived stem cells (Fig. 4C, D). MiR-509-3p markedly arrested A549dereived stem cells in G0/G1 phase (Fig. 4E). MiR-509-3p was decreased in A549/R cells compared with A549 cells (Fig. 4F), indicating that miR-509-3p functions as an essential regulator of chemo-resistance in NSCLC cells. Furthermore, miR-509-3p-overexpressed A549-dereived stem cells were incubated with cisplatin at different concentration, and CCK-8 assays showed that increasing concentration of cisplatin significantly decreased cell viability of miR-509-3p-overexpressed A549-dereived stem cells (Fig. 4G). Annexin V-FITC/PI assays and qRTPCR analysis showed that miR-509-3p-overexpression markedly elevated apoptosis of A549-dereived stem cells by promoting expression of Bax and cleaved-caspase-3, and down-regulating Bcl-2 expression (Fig. 4H-J). Furthermore, miR-509-3p-overexpression significantly decreased colony formation of A549-dereived stem cells by inhibiting expression of cell growth-associated genes Cyclin A1, Cyclin B1, and PCNA (Fig. 4K-M).

\section{Overexpression of ASAP1-IT1 blocked the effect} of miR-509-3p on cancer stem cells both in vitro and in vivo Based on the above results, overexpression of miR509-3p reduced the stemness, cisplatin resistance and growth, and promoted apoptosis of A549-dereived stem cells both in vitro and in vivo. Analysis of sphere formation indicated that overexpression of ASAP1-IT1 significantly overturned the effect of miR-509-3p in sphere formation and restored expression of stemness-associated genes including SOX2, CD44, and CD133 (Fig. 5A, B). ASAP1-IT1 overexpression reversed miR-509-3pinduced apoptosis by restoring miR-509-3p-controlled expression of apoptotic genes (Fig. 5C, D). Similarly, ASAP1-IT1 overexpression abolished the suppressive effect of miR-509-3p on cell growth by recovering miR509-3p-mediated expression of cell growth-related genes including Cyclin A1, Cyclin B1, and PCNA (Fig. 5E, F).

Moreover, it was found that overexpression of miR509-3p significantly decreased tumor growth whereas overexpression of ASAP1-IT1 could block the miR509-3p-mediated inhibitory activity on tumor growth in vivo xenografts (Fig. 5G-I). Finally, ASAP1-IT1 also reversed miR-509-3p-controlled expression of genes involved in stemness, cell growth, and cell apoptosis in tumors (Fig. 5J).

\section{YAP1 is regulated by miR-509-3p and ASAP1-IT1}

To further explore the potential molecular mechanism of ASAP1-IT1 and miR-509-3p interaction in NSCLC 

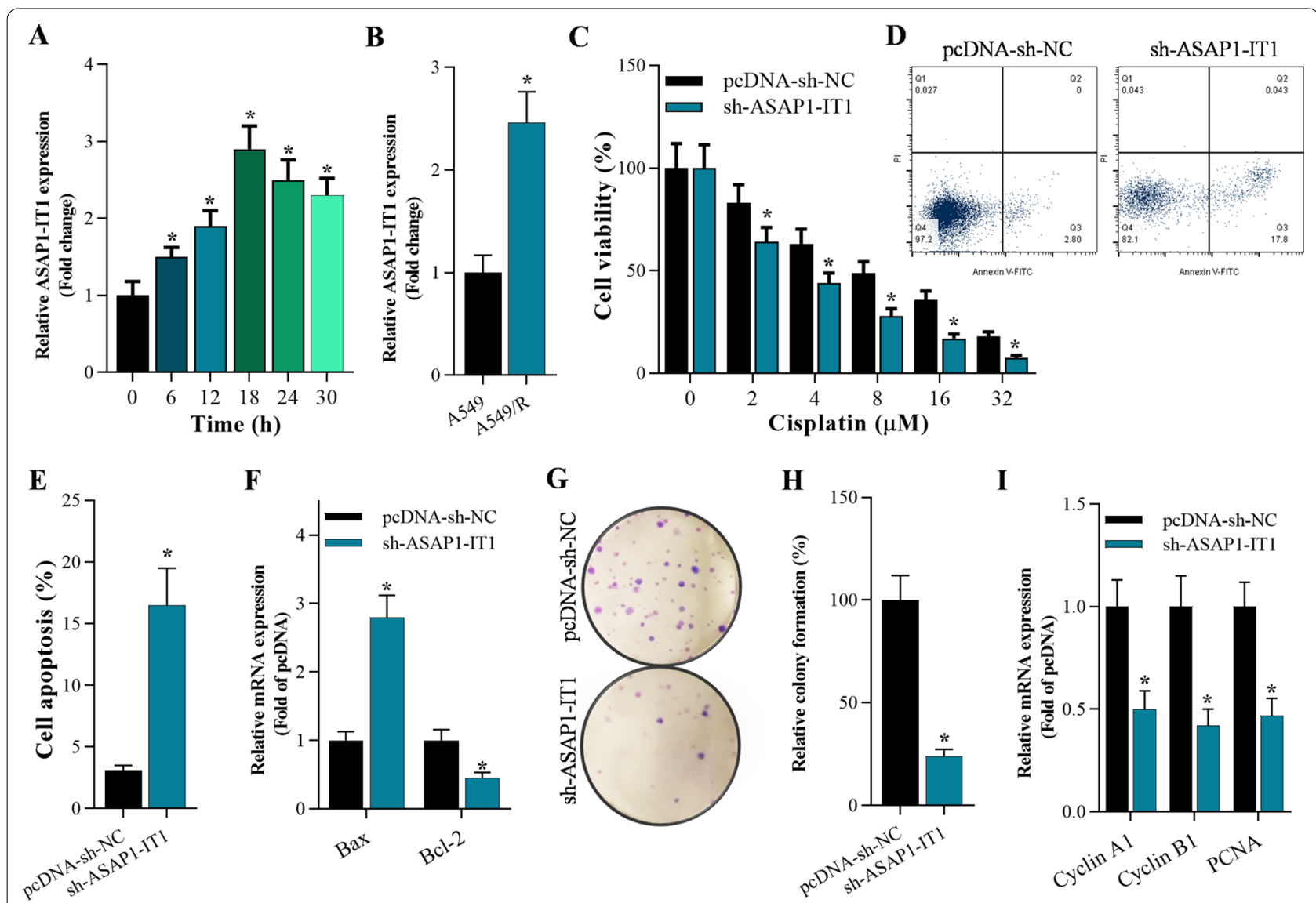

Fig. 2 Knockdown of ASAP1-IT1suppressed cisplatin resistance and cell growth of cancer stem cells and interfering ASAP1-IT1 promoted apoptosis. qRT-PCR analysis of ASAP1-IT1 expression in A A549 cells post incubation with $4 \mu \mathrm{M}$ cisplatin at different times $(0 \mathrm{~h}, 6 \mathrm{~h}, 12 \mathrm{~h}, 18 \mathrm{~h}, 24 \mathrm{~h}, 30 \mathrm{~h})$, ${ }^{*} p<0.01$ compared with $0 \mathrm{~h}$ group and B A549 and cisplatin-resistant A549/R cells, ${ }^{*} p<0.01$ compared with A549. C CCK-8 assay on the cell viability of ASAP1-IT1 knockdown A549/R cells incubated with cisplatin at various concentration $(0 \mu \mathrm{M}, 4 \mu \mathrm{M}, 8 \mu \mathrm{M}, 16 \mu \mathrm{M}, 32 \mu \mathrm{M})$, ${ }^{*} p<0.01$ compared with pcDNA-sh-NC. D, E Annexin V-FITC/PI staining of A549-dereived stem cells $48 \mathrm{~h}$ post infection, ${ }^{*} p<0.01$ compared with pcDNA-sh-NC. $\mathbf{F}$ qRT-PCR analysis of expression of apoptosis-associated genes (Bax and BCl-2) $48 \mathrm{~h}$ after infection in A549-dereived stem cells, ${ }^{*} p<0.01$ compared with pcDNA-sh-NC. G, H Colony formation assay on cell growth of A549-dereived stem cells after 15 days of culture, ${ }^{*} p<0.01$ compared with pcDNA-sh-NC. I qRT-PCR analysis on the expression of proliferation-associated genes (Cyclin A1, Cyclin B1, and PCNA) after $48 \mathrm{~h}$ infection in A549-dereived stem cells, ${ }^{*} p<0.01$ compared with pcDNA-sh-NC

progression, we explored the downstream molecule of miR-509-3p using online bioinformatics analysis. YAP1 was identified as a target gene of miR-509-3p (Fig. 6A). YAP1 was elevated in NSCLC tissues compared with that in adjacent tissues by qRT-PCR analysis (Fig. 6B). Meanwhile, qRT-PCR analysis also revealed that YAP1 was upregulated in spheres compared with adherent cancer cells (Fig. 6C). Luciferase reporter assay demonstrated that miR-509-3p suppressed luciferase activity of pmirGLOYAP1-3'UTR-WT, and it failed to affect the luciferase activity of pmirGLO-YAP1-3'UTR-Mut which contained the mutated binding sites of miR-509-3p on YAP1 $3^{\prime}$ UTR (Fig. 6D). In addition, overexpression of miR-509-3p significantly reduced YAP1expression at the mRNA and protein levels (Fig. 6E, F). Moreover, overexpression of ASAP1-IT1 enhancedYAP1 expression (Fig. 6D-F), and significantly blocked miR-509-3p-controlled YAP1 expression evidenced by luciferase reporter assay, qRTPCR, and Western blot (Fig. 6D-F).

\section{Overexpression of YAP1 reversed miR-509-3p function on cancer cell stemness, cell growth, and apoptosis in A549-derived stem cells}

To determine whether YAP1 is required for the function of miR-509-3p, we overexpressed YAP1 and miR-509-3p in A549-dereived stem cells. It was found that overexpression of YAP1 reversed the inhibitory effect of miR509-3p on stemness evidenced by sphere formation and restoring expression of the stemness-associated genes SOX2, CD44, and CD133 in A549-dereived stem cells 


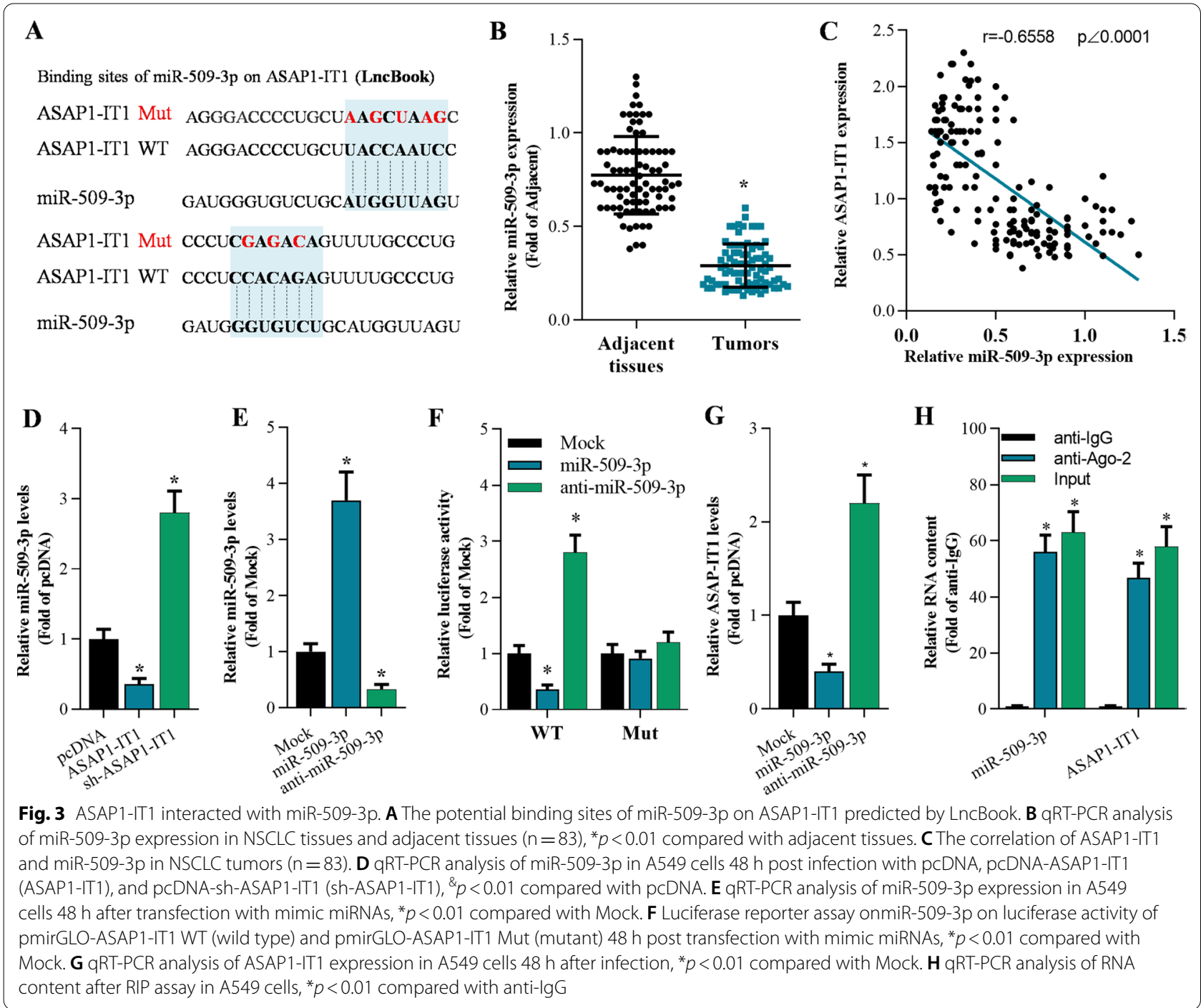

(Fig. 7A, B). Overexpression of YAP1significantly attenuated miR-509-3p-induced apoptosis by restoring miR509-3p-controlled expression of apoptotic genes Bax, Bcl-2, caspase-3 (Fig. 7C, D). Furthermore, YAP1 overexpression abolished the suppressive effect of miR-509-3p on cell growth in A549-dereived stem cells via recovering expression of cell growth-related genes Cyclin A1, Cyclin B1, and PCNA (Fig. 7E, F).

\section{Discussion}

Increasing evidence have demonstrated that cancer stem cells participate in the aggressive and destructive behaviors of lung cancers including NSCLC, a main cause of cancer-induced death worldwide $[2,3,35,36]$. The cancer stem cells significantly increase the recurrence of NSCLC after surgery or radiotherapy [4-6]. The cancer stem cells possess the properties of self-renewal, cancer initiation, and cancer progression [7]. Cancer stem cells also aggravate multi-drug resistance in lung cancer [8]. Therefore, exploring cancer stem cell-related potential molecular mechanism in NSCLC progression is critical, as it would contribute to the treatment of patients with NSCLC.

It has been reported that a variety of IncRNAs are involved in the progression of NSCLC $[14,15,37,38]$. As reported in previous studies, ASAP1-IT1 is upregulated in NSCLC and promotes cancer proliferation, invasion and migration [22]. Consistent with this report, our preliminary sequencing data shows that ASAP1-IT1 was one of the top 20 up-regulated lncRNA in NSCLC with poor clinical outcome (data not shown). Moreover, ASAP1IT1 was validated to be upregulated in NSCLC tumors, cancer cells, and A549 cell spheres. Cancer stem cells 


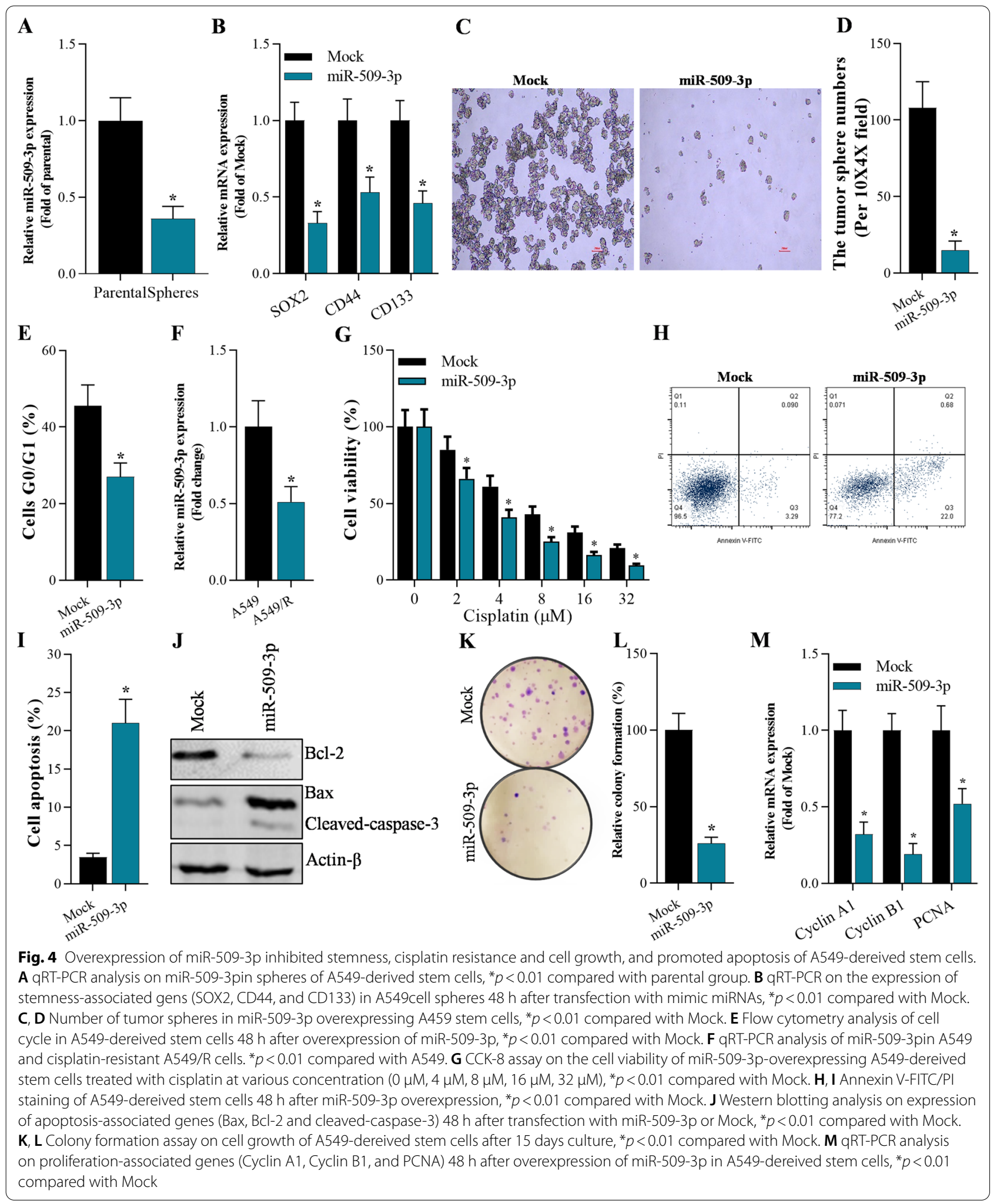


A

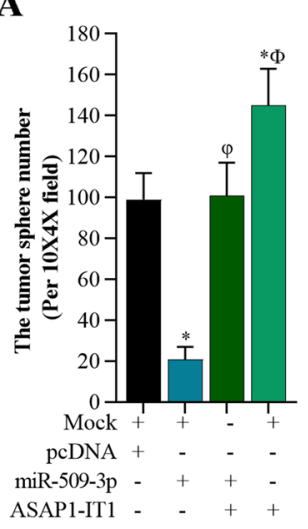

B

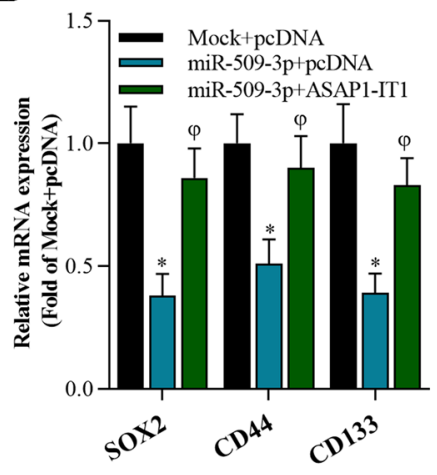

C

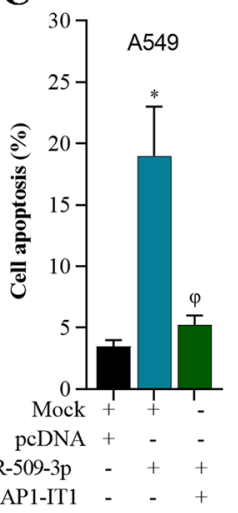

D

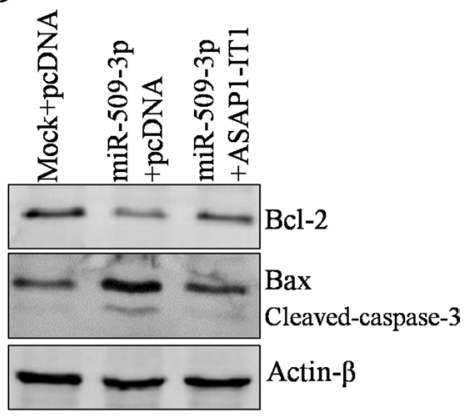

E

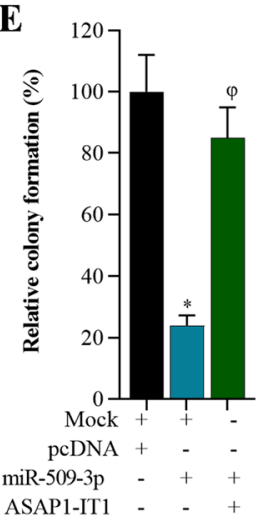

F

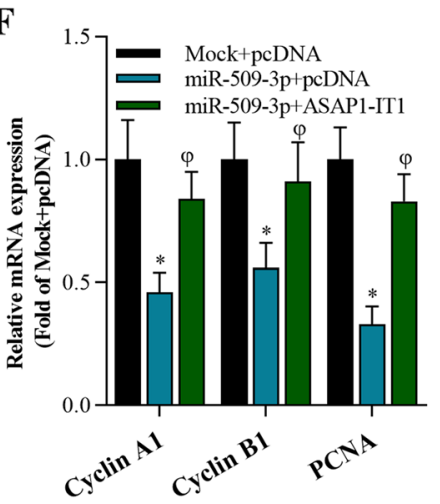

G

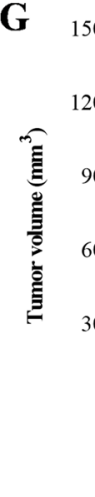

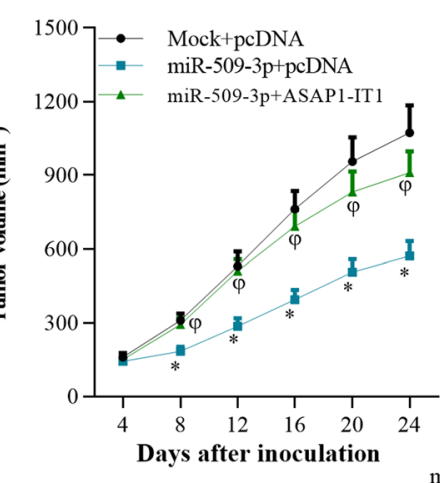

I

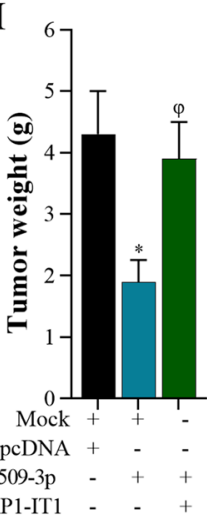

\section{H}

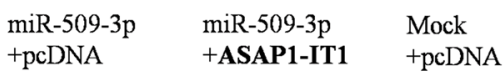

J $\quad 5^{5} 7$ Mock+pcDNA
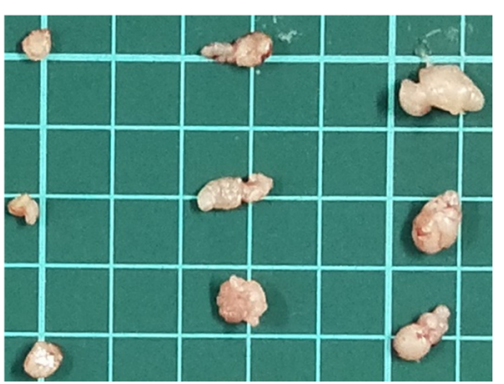

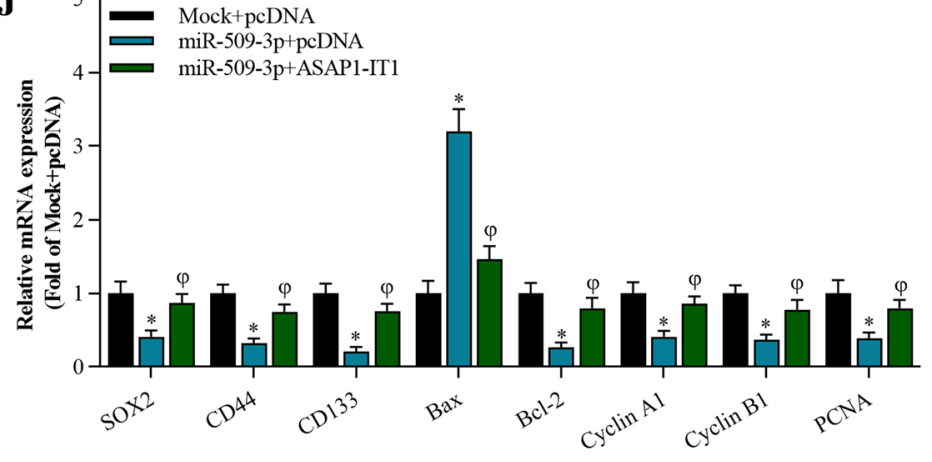

Fig. 5 Overexpression of ASAP1-IT1 blocked miR-509-3p-mediated cell functions in cancer stem cells both in vitro and in vivo. A Number of A549 cell tumor spheres after expression of Mock, pcDNA, miR-509-3p, and ASAP1-IT1, ${ }^{*} p<0.01$ compared with Mock + pcDNA, $\varphi p<0.01$ compared with miR-509-3p+pcDNA, $\Phi p<0.01$ compared with miR-509-3p + ASAP1-IT1. B qRT-PCR analysis on stemness-related genes (SOX2, CD44, and CD133) in A549 stem cells, ${ }^{*} p<0.01$ compared with Mock + pcDNA, $\varphi p<0.01$ compared with miR-509-3p + pcDNA. C Annexin V-FITC/PI staining of A549 stem cells with Mock, pcDNA, miR-509-3p, and ASAP1-IT1, ${ }^{*} p<0.01$ compared with Mock + pcDNA, $\varphi p<0.01$ compared with miR-509-3p+pcDNA. D Western blotting analysis on apoptosis-associated genes (Bax, Bcl-2, and cleaved-caspase-3) in A549 stem cells, ${ }^{*} p<0.01$ compared with Mock + pcDNA, $\varphi p<0.01$ compared with miR-509-3p + pcDNA. E Colony formation assay on cell growth after 15 days culture, ${ }^{*} p<0.01$ compared with Mock + pcDNA, $\varphi p<0.01$ compared with miR-509-3p+pcDNA. F qRT-PCR analysis of growth-associated genes (Cyclin A1, Cyclin B1, and PCNA) in A549 stem cells, ${ }^{*} p<0.01$ compared with Mock + pcDNA, $\varphi p<0.01$ compared with miR-509-3p+pcDNA. G Tumor volume in nude mice at the indicated time after inoculation, ${ }^{*} p<0.01$ compared with Mock + pcDNA, $\varphi p<0.01$ compared with miR-509-3p+pcDNA. H Photo of harvested tumors at the 24th day after inoculation. I Tumor weight at the 24th day after inoculation, ${ }^{*} p<0.01$ compared with Mock + pcDNA, $\varphi p<0.01$ compared with miR-509-3p + pcDNA. J qRT-PCR analysis on stemness-associated genes (SOX2, CD44, and CD133), apoptosis-associated genes (Bax and Bcl-2), and growth-associated genes (Cyclin A1, Cyclin B1, and PCNA) in tumors, ${ }^{*} p<0.01$ compared with Mock $+p c D N A, \varphi p<0.01$ compared with miR-509-3p+ pcDNA 
was reported to efficiently affect multi-drug resistance in NSCLC [8, 39-42]. Here we demonstrated that knockdown of ASAP1-IT1 significantly suppressed cancer cell stemness of NSCLC cells and increase chemoresistance to cisplatin in NSCLC cells. ASAP1-IT1 was also overexpressed in A549/R cells, suggesting that ASAP1-IT1 could be associated with cisplatin resistance. Knockdown of ASAP1-IT1significantly inhibited cancer stem cell colony formation and A549 cancer cell stemness. Further studies demonstrated that knockdown of ASAP1IT1 suppressed expression of stem cell biomarkers SOX2, CD34, and CD133 in A549-dereived stem cells. Then, downregulating ASAP1-IT1 expression decreased expression of cell growth-associated genes Cyclin A1, Cyclin B1, and PCNA, and elevated expression of cell apoptosis related genes Bax and caspase- 3 and reduced anti-apoptotic Bcl-2 expression in A549-dereived stem cells. The in vivo experiments proved that knockdown of ASAP1-IT1 significantly inhibited tumor growth in nude mice. Thus, these in vitro and in vivo findings suggested that ASAP1-IT1 acted as an oncogene to regulate cancer cell stemness, cell growth and cell apoptosis in NSCLC.
Down-regulation of ASAP1-IT1 could be a good strategy to fight against NSCLC.

LncRNAs exert their activity in cancers often by functioning as sponges of miRNAs $[15,43]$. In this study, ASAP1-IT1 was firstly predicted to interact with miR-509-3p. The interaction between ASAP1-IT1 and miR-509-3p was proved by luciferase RIP assays. Previous studies have revealed that miR-509-3p inhibits tumor growth in multiple types of cancers. For example, miR-509-3p improves sensitivity of cancer cells to platinum in ovarian cancer $[23,24,44]$, and it depresses cell proliferation and invasion via down-regulating X-linked inhibitor of apoptosis in glioma [28]. MiR-509 promotes hepatoma progression by activating NF- $\mathrm{BB}$ (nuclear factor kappa B) signaling pathway. However, the role of miR-509-3p in the stemness of NSCLC has not been investigated. In consistent with previous studies, miR-509-3p was significantly down-regulated in NSCLC tissues, NSCLC cells, A549 spheres, and in A549/R cells. Overexpression of miR509-3p suppressed sphere formation and cell growth, and increased cell apoptosis of A549-dereived stem

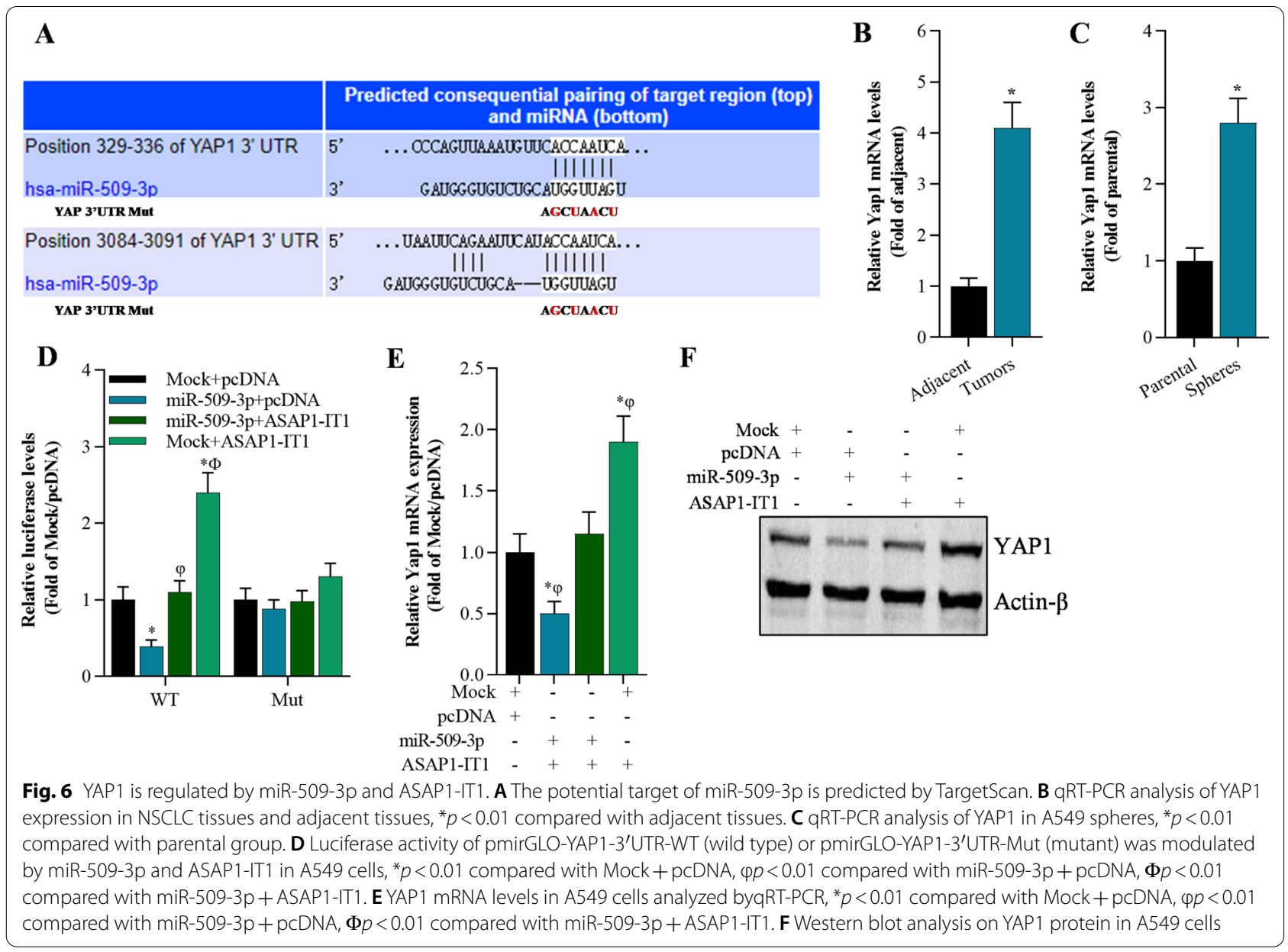



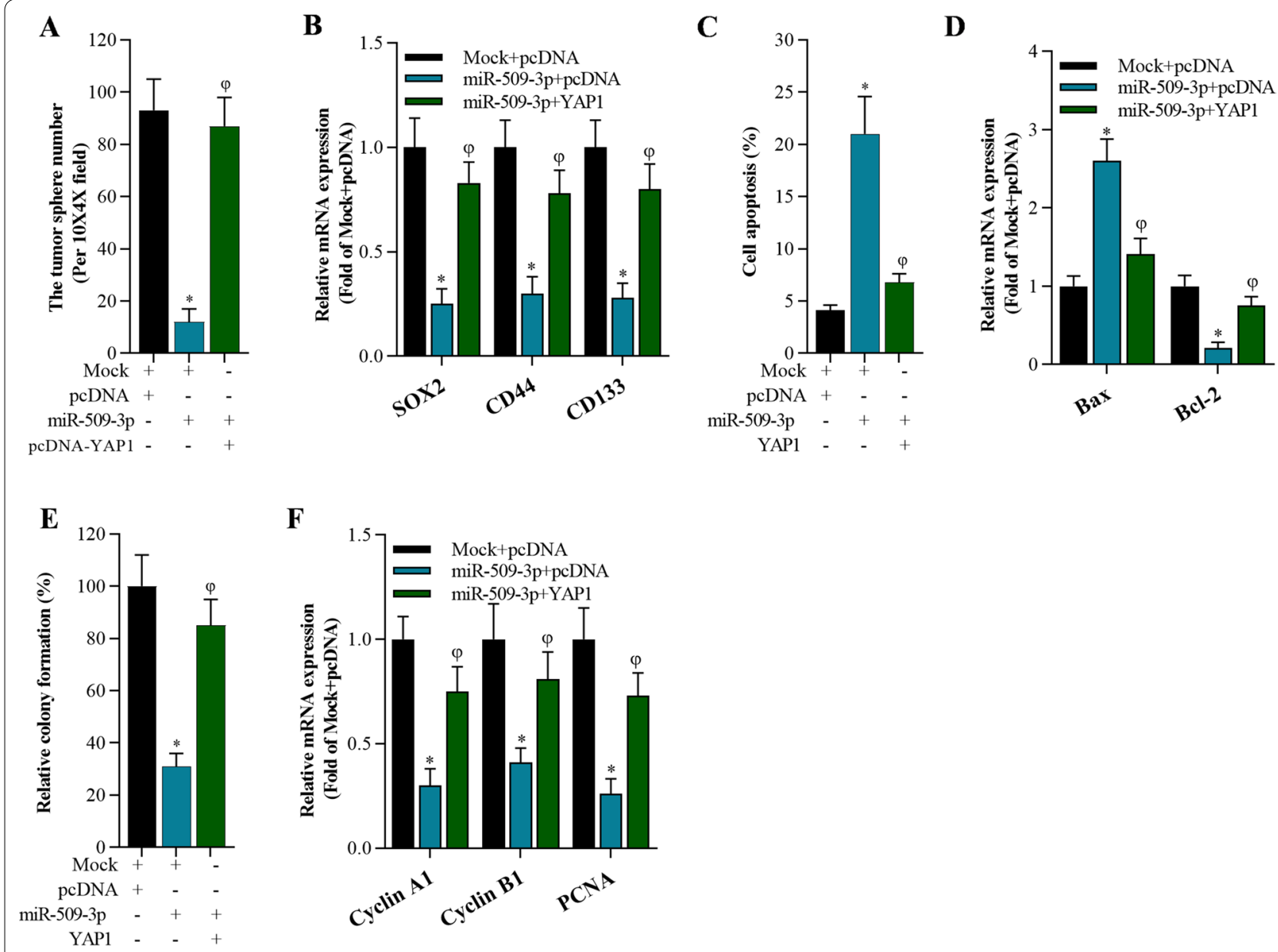

Fig. 7 Overexpression of YAP1 reversed miR-509-3p-mediated cancer cell stemness, cell growth, and apoptosis of A549-derived stem cells. A Number of tumorA549 spheres after transfection with Mock, pcDNA, miR-509-3p, and YAP1, ${ }^{*} p<0.01$ compared with Mock + pcDNA, $\varphi p<0.01$ compared with miR-509-3p + pcDNA. B qRT-PCR analysis on stemness-related genes (SOX2, CD44, and CD133) $48 \mathrm{~h}$ after transfection in A549-derived stem cells, ${ }^{*} p<0.01$ compared with Mock + pcDNA, $\varphi p<0.01$ compared with miR-509-3p+pcDNA. C Annexin V-FITC/PI staining of A549-derived stem cells after transfection with Mock, pcDNA, miR-509-3p, and YAP1, ${ }^{*} p<0.01$ compared with Mock + pcDNA, $\varphi p<0.01$ compared with miR-509-3p + pcDNA. D qRT-PCR analysis on apoptosis-associated genes (Bax, Bcl-2, and caspase-3) in A549-derived stem cells, ${ }^{*} p<0.01$ compared with Mock+ pcDNA, $\varphi p<0.01$ compared with miR-509-3p + pcDNA. E Colony formation assay on cell growth of A549-derived stem cells after 15 days culture, ${ }^{*} p<0.01$ compared with Mock + pcDNA, $\varphi p<0.01$ compared with miR-509-3p+pcDNA. F qRT-PCR analysis of growth-associated f genes (Cyclin A1, Cyclin B1, and PCNA) in stem cells of A549 cells, ${ }^{*} p<0.01$ compared with Mock + pcDNA, $\varphi p<0.01$ compared with miR-509-3p+ pcDNA

cells. Also, overexpression of miR-509-3p decreased expression of SOX2, CD44, and CD133, and enhanced expression of Bax and caspase- 3 while repressed Bcl-2 expression in cancer cells. Furthermore, overexpression of miR-509-3p suppressed tumor growth in nude mice. These results implied that miR-509-3p was a tumor suppressor, and overexpression of miR-509-3p could offer a novel approach to prevent NSCLC progression. Furthermore, overexpression of ASAP1-IT1 significantly blocked overexpression of miR-224-3p-mediated inhibition of cancer stem cell-like properties and cell growth of A549-dereived stem cells both in vitro and in vivo. Additionally, overexpression of ASAP1-IT1 abolished miR-509-3p-induced cancer cell apoptosis of A549-dereived stem cells both in vitro and in vivo, indicating that the interaction between ASAP1-IT1 and miR-509-3pis involved in regulation of cancer cell stemness and NSCLC progression.

Bioinformatics analysis showed that miR-509-3p could target the $3^{\prime} \mathrm{UTR}$ of YAP1, which is an oncogene in the Hippo signaling pathway involved in human cancers [34]. Pan et al. reported that miR-509-3p attenuates ovarian cancer cellular migration and formation of multi-cellular spheroids by targeting YAP144. Our 
study also demonstrates that miR-509-3p abrogates cancer cell stemness via downregulation of YAP1. Our results were in consistent with the previous studies which supported that YAP1 is an oncogene and aggravates drug resistance and cancer cell stemness in NSCLC [29-33, 45, 46]. Moreover, we also observed that interaction of ASAP1-IT1 with miR-509-3p led to reciprocally inhibition. These findings demonstrated that YAP1 is involved in ASAP1-IT1/miR-509-3p interaction and plays an important role in cancer cell stemness and progression of NSCLC.

\section{Conclusion}

In conclusion, ASAP1-IT1 is up-regulated in NSCLC and promotes cancer cell stemness by suppressing miR509-3p. YAP1 is modulated by ASAP1-IT1 and miR509-3p in A549-dereived stem cells. ASAP1-IT1 and miR-509-3p could be potential therapeutic targets of NSCLC (Additional file 1: Figure S1).

\begin{abstract}
Abbreviations
ASAP1-IT1: ASAP1 Intronic Transcript 1; NSCLC: Non-small cell lung cancer; CSCs: Cancer stem cells; IncRNAs: Long noncoding RNAs; miR-509-3p: MicroRNA-509-3p; RIP: RNA immunoprecitation; H\&E: Hematoxylin-eosin; CCK-8: Cell counting kit-8; Linc00673/00473: Long intergenic non-protein coding RNA 673/00473; CAMP/CREB: Adenosine monophosphate/CAMP-response element binding protein; LKB1: Liver kinase B1; DGC5: DiGeorge syndrome critical region gene 5; FENDFRR: FOXF1 adjacent non-coding developmental regulatory RNA; MDR1: Multi-drug resistance gene 1; PTEN/AKT: Phosphatase and tensin homolog/AKT serine/threonine kinase 1; XIAP: X-linked inhibitor of apoptosis; YAP1: Yes associated protein 1.
\end{abstract}

\section{Supplementary Information}

The online version contains supplementary material available at https://doi. org/10.1186/s12935-021-02270-7.

Additional file 1. ASAP1-IT1 increases cancer cell stemness by regulating miR-509-3p/YAP1 signal pathway in NSCLC cells.

\section{Acknowledgements}

We acknowledge the language editing by UNIWINSCI. Inc, and thank the patients enrolled in this study.

\section{Authors' contributions}

WZ, KC and $Y L$ conceived and designed the study. YY, YL, LZ, JL, HL and BL performed experiments. JL, MY and BL searched the literature. WZ and KC performed data extraction and analysis. WZ and KC drafted the manuscript. All authors revised the final manuscript. All authors read and approved the final manuscript.

\section{Funding}

This work was supported by the National Natural Science Foundation of China (81602636 and 81802682), the Nanjing medical science and technology development project (ZKX15049), the Key project of science of Sichuan Education Department (18ZA0164), the Natural Science Foundation of Chengdu Medical College (CYZ18-04), the Natural Science Foundation of Jiangsu Province (BK 20180199) and the Miaozi project of science and Technology Department of Sichuan Province (2018RZ0095).

\section{Availability of data and materials}

The datasets supporting the conclusions of this article are included within the article and could be obtained from the corresponding author if necessary.

\section{Declarations}

Ethics approval and consent to participate

The specimen collection was approved by the Ethics Committee of Chengdu Medical College (approved ID: BR2Ore19), and each participant signed an informed consent form. The animal experiments were approved by the Research Ethics Committee of Chengdu Medical College (approved animal Protocol No. CMC20LM22)

\section{Consent for publication}

Not applicable.

\section{Competing interests}

The authors declare that they have no competing interests.

\section{Author details}

'Department of Pharmacy, West China Second University Hospital, Sichuan University, Chengdu, China. ${ }^{2}$ Evidence-Based Pharmacy Center, West China Second University Hospital, Sichuan University, Chengdu, China. ${ }^{3}$ Key Laboratory of Birth Defects and Related Diseases of Women and Children, Sichuan University, Ministry of Education, Chengdu, China. ${ }^{4}$ Department of Respiratory Medicine, The First Affiliated Hospital of Chengdu Medical College, Chengdu, China. ${ }^{5}$ School of Laboratory Medicine Chengdu Medical College, Chengdu, China. ${ }^{6}$ Department of Orthopedic Surgery, The First Affiliated Hospital of Soochow University, Suzhou, China. ${ }^{7}$ Department of Refractive Surgery, Chengdu Aier Eye Hospital, Chengdu, China. ${ }^{8}$ Department of Biomedical Sciences, City University of Hong Kong, Hong Kong, China.

Received: 22 May 2021 Accepted: 16 October 2021

Published online: 29 October 2021

\section{References}

1. Sung H, Ferlay J, Siegel RL, et al. Global cancer statistics 2020: GLOBOCAN estimates of incidence and mortality worldwide for 36 cancers in 185 countries. CA Cancer J Clin. 2021;71(3):209-49.

2. Chen W, Zheng R, Baade PD, et al. Cancer statistics in China, 2015. CA Cancer J Clin. 2016;66(2):115-32.

3. Wood SL, Pernemalm M, Crosbie PA, Whetton AD. Molecular histology of lung cancer: from targets to treatments. Cancer Treat Rev. 2015:41(4):361-75.

4. Auperin A, Le Pechoux C, Rolland E, et al. Meta-analysis of concomitant versus sequential radiochemotherapy in locally advanced non-small-cell lung cancer. J Clin Oncol. 2010;28(13):2181-90.

5. Sourisseau T, Hassan KA, Wistuba I, et al. Lung cancer stem cell: fancy conceptual model of tumor biology or cornerstone of a forthcoming therapeutic breakthrough? J Thorac Oncol. 2014;9(1):7-17.

6. Kitamura H, Okudela K, Yazawa T, Sato H, Shimoyamada H. Cancer stem cell: implications in cancer biology and therapy with special reference to lung cancer. Lung Cancer. 2009;66(3):275-81.

7. Reya T, Morrison SJ, Clarke MF, Weissman IL. Stem cells, cancer, and cancer stem cells. Nature. 2001:414(6859):105-11.

8. Singh A, Settleman J. EMT, cancer stem cells and drug resistance: an emerging axis of evil in the war on cancer. Oncogene. 2010;29(34):4741-51.

9. Li C, Zhao W, Pan X, et al. LncRNA KTN1-AS1 promotes the progression of non-small cell lung cancer via sponging of miR-130a-5p and activation of PDPK1. Oncogene. 2020;39(39):6157-71.

10. Yan F, Zhao W, Xu X, et al. LncRNA DHRS4-AS1 inhibits the stemness of NSCLC cells by sponging miR-224-3p and upregulating TP53 and TET1. Front Cell Dev Biol. 2020;8:585251.

11. Shao G, Zhao Z, Zhao W, et al. Long non-coding RNA MALAT1 activates autophagy and promotes cell proliferation by downregulating microRNA-204 expression in gastric cancer. Oncol Lett. 2020;19(1):805-12. 
12. Huang N, Guo W, Ren $K$, et al. LncRNA AFAP1-AS1 supresses miR-139-5p and promotes cell proliferation and chemotherapy resistance of non-small cell lung cancer by competitively upregulating RRM2. Front Oncol. 2019;9:1103.

13. Song J, Wu X, Ma R, Miao L, Xiong L, Zhao W. Long noncoding RNA SNHG12 promotes cell proliferation and activates Wnt/beta-catenin signaling in prostate cancer through sponging microRNA-195. J Cell Biochem. 2019;120(8):13066-75.

14. Yin D, Lu X, Su J, et al. Long noncoding RNA AFAP1-AS1 predicts a poor prognosis and regulates non-small cell lung cancer cell proliferation by epigenetically repressing p21 expression. Mol Cancer. 2018;17(1):92.

15. Lu W, Zhang H, Niu Y, et al. Long non-coding RNA linc00673 regulated nonsmall cell lung cancer proliferation, migration, invasion and epithelial mesenchymal transition by sponging miR-150-5p. Mol Cancer. 2017;16(1):118.

16. Chen Z, Li JL, Lin S, et al. CAMP/CREB-regulated LINC00473 marks LKB1-inactivated lung cancer and mediates tumor growth. J Clin Invest. 2016;126(6):2267-79.

17. Wang R, Dong HX, Zeng J, Pan J, Jin XY. LncRNA DGCR5 contributes to CSClike properties via modulating miR-330-5p/CD44 in NSCLC. J Cell Physiol. 2018;233(9):7447-56.

18. Gong W, Su Y, Liu Y, Sun P, Wang X. Long non-coding RNA Linc00662 promotes cell invasion and contributes to cancer stem cell-like phenotypes in lung cancer cells. J Biochem. 2018;164(6):461-9.

19. Gong F, Dong D, Zhang T, Xu W. Long non-coding RNA FENDRR attenuates the stemness of non-small cell lung cancer cells via decreasing multidrug resistance gene 1 (MDR1) expression through competitively binding with RNA binding protein HuR. Eur J Pharmacol. 2019;853:345-52.

20. Guo L, Sun C, Xu S, et al. Knockdown of long non-coding RNA linc-ITGB1 inhibits cancer stemness and epithelial-mesenchymal transition by reducing the expression of Snail in non-small cell lung cancer. Thorac Cancer. 2019;10(2):128-36.

21. Miao F, Chen J, Shi M, Song Y, Chen Z, Pang L. LncRNA HAND2-AS1 inhibits non-small cell lung cancer migration, invasion and maintains cell stemness through the interactions with TGF-beta1. 2019. Biosci Rep. https://doi.org/ 10.1042/BSR20181525.

22. Zhang L, Shi SB, Zhu Y, Qian TT, Wang HL. Long non-coding RNA ASAP1-IT1 promotes cell proliferation, invasion and metastasis through the PTEN/AKT signaling axis in non-small cell lung cancer. Eur Rev Med Pharmacol Sci. 2018;22(1):142-9.

23. Yang L, Xue Y, Liu J, et al. Long noncoding RNA ASAP1-IT1 promotes cancer stemness and predicts a poor prognosis in patients with bladder cancer. Neoplasma. 2017;64(6):847-55

24. Guo L, Zhou Y, Chen Y, Sun H, Wang Y, Qu Y. LncRNA ASAP1-IT1 positively modulates the development of cholangiocarcinoma via hedgehog signaling pathway. Biomed Pharmacother. 2018;103:167-73.

25. Niu L, Ni H, Hou Y, Du Q, Li H. miR-509-3p enhances platinum drug sensitivity in ovarian cancer. Gene. 2019;686:63-7.

26. Chen W, Du J, Li X, et al. miR-509-3p promotes cisplatin-induced apoptosis in ovarian cancer cells through the regulation of anti-apoptotic genes. Pharmacogenomics. 2017;18(18):1671-82

27. Sun J, Li J, Zhang W, et al. MicroRNA-509-3p inhibits cancer cell proliferation and migration via upregulation of XIAP in gastric cancer cells. Oncol Res. 2017;25(3):455-61

28. Du P, Luan X, Liao Y, et al. MicroRNA-509-3p inhibits cell proliferation and invasion via downregulation of $X$-linked inhibitor of apoptosis in glioma. Oncol Lett. 2018;15(1):1307-12.

29. Zhang M, Zeng J, Zhao Z, Liu Z. Loss of MiR-424-3p, not miR-424-5p, confers chemoresistance through targeting YAP1 in non-small cell lung cancer. Mol Carcinog. 2017;56(3):821-32.

30. LuT, Li Z, Yang Y, et al. The Hippo/YAP1 pathway interacts with FGFR1 signaling to maintain stemness in lung cancer. Cancer Lett. 2018;423:36-46.

31. Zhang MY, Lin J, Kui YC. MicroRNA-345 suppresses cell invasion and migration in non-small cell lung cancer by directly targeting YAP1. Eur Rev Med Pharmacol Sci. 2019;23(6):2436-43.
32. Zou H, Wang S, Wang S, et al. SOX5 interacts with YAP1 to drive malignant potential of non-small cell lung cancer cells. Am J Cancer Res. 2018:8(5):866-78.

33. Zhang Y, Zhang $\mathrm{Q}$, Chen H, Wang C. BCL9 promotes epithelial mesenchymal transition and invasion in cisplatin resistant NSCLC cells via beta-catenin pathway. Life Sci. 2018;208:284-94.

34. WuY, Hou Y, Xu P, et al. The prognostic value of YAP1 on clinical outcomes in human cancers. Aging. 2019;11:8681.

35. Siegel RL, Miller KD, Jemal A. Cancer statistics, 2017. CA Cancer J Clin. 2017;67(1):7-30

36. Boolell V, Alamgeer M, Watkins DN, Ganju V. The evolution of therapies in non-small cell lung cancer. Cancers. 2015;7(3):1815-46.

37. Chang ZW, Jia YX, Zhang WJ, et al. LncRNA-TUSC7/miR-224 affected chemotherapy resistance of esophageal squamous cell carcinoma by competitively regulating DESC1. J Exp Clin Cancer Res. 2018;37(1):56.

38. Fatica A, Bozzoni I. Long non-coding RNAs: new players in cell differentiation and development. Nat Rev Genet. 2014;15(1):7-21.

39. Wang X, Meng Q, Qiao W, et al. miR-181 b/Notch2 overcome chemoresistance by regulating cancer stem cell-like properties in NSCLC. Stem Cell Res Ther. 2018;9(1):327.

40. Yao W, Wang $\mathrm{L}$, Huang $\mathrm{H}$, et al. All-trans retinoic acid reduces cancer stem cell-like cell-mediated resistance to gefitinib in NSCLC adenocarcinoma cells. BMC Cancer. 2020;20(1):315.

41. Cao S, Wang Z, Gao X, et al. FOXC1 induces cancer stem cell-like properties through upregulation of beta-catenin in NSCLC. J Exp Clin Cancer Res. 2018;37(1):220.

42. de Aberasturi AL, Redrado M, Villalba M, et al. TMPRSS4 induces cancer stem cell-like properties in lung cancer cells and correlates with ALDH expression in NSCLC patients. Cancer Lett. 2016:370(2):165-76.

43. Du Z, Sun T, Hacisuleyman E, et al. Integrative analyses reveal a long noncoding RNA-mediated sponge regulatory network in prostate cancer. Nat Commun. 2016;7:10982.

44. Pan Y, Robertson G, Pedersen L, et al. Correction: miR-509-3p is clinically significant and strongly attenuates cellular migration and multi-cellular spheroids in ovarian cancer. Oncotarget. 2017;8(10):17406.

45. Wu C, Xu B, Yuan P, et al. Genome-wide interrogation identifies YAP1 variants associated with survival of small-cell lung cancer patients. Cancer Res. 2010;70(23):9721-9.

46. Nishikawa E, Osada H, Okazaki Y, et al. miR-375 is activated by ASH1 and inhibits YAP1 in a lineage-dependent manner in lung cancer. Cancer Res. 2011;71(19):6165-73.

\section{Publisher's Note}

Springer Nature remains neutral with regard to jurisdictional claims in published maps and institutional affiliations.

Ready to submit your research? Choose BMC and benefit from:

- fast, convenient online submission

- thorough peer review by experienced researchers in your field

- rapid publication on acceptance

- support for research data, including large and complex data types

- gold Open Access which fosters wider collaboration and increased citations

- maximum visibility for your research: over 100M website views per year

At BMC, research is always in progress.

Learn more biomedcentral.com/submissions 